\title{
The sea level fingerprint of recent ice mass fluxes
}

\author{
J. Bamber ${ }^{1}$ and R. Riva ${ }^{2,3}$ \\ ${ }^{1}$ Bristol Glaciology Centre, University of Bristol, UK \\ ${ }^{2}$ Delft Institute of Earth Observation and Space Systems, Delft University of Technology, The Netherlands \\ ${ }^{3}$ Faculty of Geoscience, Utrecht University, The Netherlands
}

Received: 30 July 2010 - Published in The Cryosphere Discuss.: 3 September 2010

Revised: 15 December 2010 - Accepted: 16 December 2010 - Published: 21 December 2010

\begin{abstract}
The sea level contribution from glacial sources has been accelerating during the first decade of the 21 st Century (Meier et al., 2007; Velicogna, 2009). This contribution is not distributed uniformly across the world's oceans due to both oceanographic and gravitational effects. We compute the sea level signature for ice mass fluxes due to changes in the gravity field, Earth's rotation and related effects for the nine year period 2000-2008. Mass loss from Greenland results in a relative sea level (RSL) reduction for much of North Western Europe and Eastern Canada. RSL rise from this source is concentrated around South America. Losses in West Antarctica marginally compensate for this and produce maxima along the coastlines of North America, Australia and Oceania. The combined far-field pattern of wastage from all ice melt sources, is dominated by losses from the ice sheets and results in maxima at latitudes between $20^{\circ} \mathrm{N}$ and $40^{\circ} \mathrm{S}$ across the Pacific and Indian Oceans, affecting particularly vulnerable land masses in Oceania. The spatial pattern of RSL variations from ice mass losses used in this study is time-invariant and cumulative. Thus, sea level rise, based on the gravitational effects from the ice losses considered here, will be amplified for this sensitive region.
\end{abstract}

\section{Introduction}

It has been suggested that the ocean dynamic response to future climate change will result in enhanced sea level rise for the northeast coastline of the United States (Yin et al., 2009) and that steric anomalies, due to increased melt from the ice sheets, will result in long-lived local RSL variations (Stammer, 2008). The geodetic effects of present-day regional ice melt and ongoing glacio isostatic adjustment

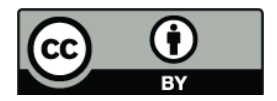

Correspondence to: J. Bamber

(j.bamber@bristol.ac.uk)
(GIA) are, however, also not uniformly distributed across the World's oceans and have a markedly different spatial signature. The non-uniform effect on RSL of the melting of large ice masses, such as the Antarctic and Greenland ice sheets, due to changes in the Earth's gravity field was recognised more than a century ago (Woodward, 1888). The original theory has been updated to include the effects of changes in Earth rotation, also known as true polar wander (TPW), and shoreline migration (Milne and Mitrovica, 1998). This updated theory has been used to examine the spatial pattern in relative sea level for a hypothetical wastage of large ice masses and to infer the mean rate of loss from Greenland over the 20th Century (Mitrovica et al., 2001).

Up until recently, however, there has been limited quantitative information on the spatial pattern of mass loss from the ice sheets. Recent satellite observations, in particular from GRACE and synthetic radar aperture interferometry (InSAR), have, however, provided unprecedented insights into both the magnitude and pattern of ice loss from the three largest sources of mass to the oceans: the Greenland and Antarctic ice sheets and Alaskan glaciers (Berthier et al., 2010; Luthcke et al., 2008; Rignot et al., 2008b; van den Broeke et al., 2009). Furthermore, consistency between different approaches is now being achieved, for Greenland at least, providing greater confidence in the results (van den Broeke et al., 2009). Here, we use these detailed observations of the spatial pattern of mass loss to examine the signature of relative sea level resulting from changes to the gravity field, TPW and shoreline migration. Mountain glacier and ice cap (MG\&IC) sources from elsewhere are, individually, considerably smaller than the three regions mentioned, and combined they contribute about $27 \%$ of the total for the period 2000-2008 (Meier et al., 2007; Hock et al., 2009; Chen et al., 2007, 2009; Wouters et al., 2008). We include, therefore, estimates of these smaller sources when considering the integrated pattern of SLR from ice melt (Fig. 1). We stress, however, that we consider, here, only the gravitationally

Published by Copernicus Publications on behalf of the European Geosciences Union. 


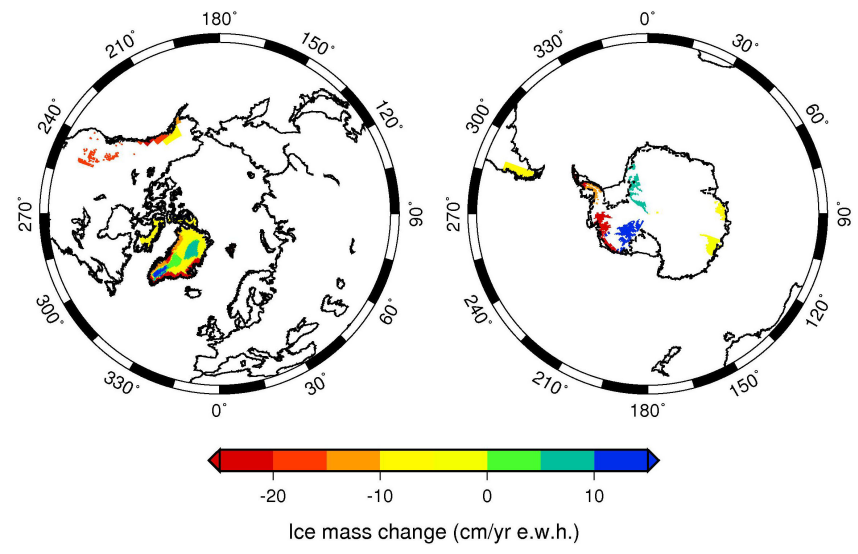

Fig. 1. Spatial distribution of ice mass trends for the regions listed in Table 1 for the period 2000-2008.

consistent signature of ice melt. We do not include the response of ocean dynamics to the additional influx of freshwater nor other changes in ocean dynamics due to predicted climate change, which can have a significant impact on RSL over decadal timescales (Yin et al., 2009; Stammer, 2008). We also do not include spatially variable thermosteric effects on sea level (Lombard et al., 2005). It is worth noting that the effect of ocean circulation is not cumulative: it has no effect on eustatic ${ }^{1}$ sea level.

\section{Methods}

In this study we consider mass trends for the first $\sim$ decade of the 21st Century (January 2000-December 2008), which requires extrapolation or interpolation of some of the time series available by $2-3$ years at the beginning or the end of the epoch as explained below. Despite agreement between methods for determining land ice mass trends mentioned earlier (van den Broeke et al., 2009), inconsistencies between authors and approaches still exist (Berthier et al., 2010; Bevis et al., 2009; Chen et al., 2009; Luthcke et al., 2008; Rignot et al., 2008a; Wu et al., 2010). These inconsistencies are due to many factors including differences in epoch, satellite product used, processing methodology (Rowlands et al., 2010), uncertainty assumptions made (Slobbe et al., 2009) and so on. It is beyond the scope of this study to discuss and explore the cause of these differences and the numbers presented in Table 1 are not aimed at providing definitive estimates of mass trends. They are, however, obtained from recent studies, with modification where justified, that we believe provide representative estimates of both the magnitude and spatial distribution of mass trends.

What is also important for determining the gravitationally consistent pattern of RSL is not just the magnitude but knowledge of the spatial distribution of mass loss for the

\footnotetext{
${ }^{1}$ Here we define eustatic variations as the global mean change in sea level due to changes in mass of the ocean.
}

larger sources considered (Fig. 1). For Antarctica we used a recent compilation of basin-scale mass budget calculations obtained from surface velocity, ice thickness and regional climate modelling data to derive the spatial distribution of losses (Rignot et al., 2008a). Results from GRACE suggest, however, a smaller average loss for the coincident period (Horwath and Dietrich, 2009; Velicogna, 2009) and, based on an analysis of elevation rates from radar altimetry (Zwally et al., 2005), we have assumed that the Abbots/Ferrigno ice shelf region along the Bellinghausen Sea sector (HH' in Rignot et al., 2008) of West Antarctica is in balance. The 2 sigma uncertainty in the mass budget estimate for this region is larger than the signal $\left(49 \pm 54 \mathrm{Gt} \mathrm{yr}^{-1}\right)$. Taking this into account we obtain a mean rate for 20002008 of $135 \mathrm{Gt} \mathrm{yr}^{-1}$. For Greenland, we use a recent estimate of annually resolved, basin-scale, mass balance that combines mass budget and gravity-derived results (van den Broeke et al., 2009). Mass budget estimates are available for years 1996, 2000, 2004-2008, while the continuous GRACE time series begins in 2003. In this case extrapolation was not required and the mean loss for the epoch we consider here is $166 \mathrm{Gt} \mathrm{yr}^{-1}$ (van den Broeke et al., 2009). For Alaska we used our own GRACE-derived mass trends for February 2003-February $2009\left(61 \mathrm{Gt} \mathrm{yr}^{-1}\right)$ and assumed the same values for 2000-2003. There is considerable inter-annual variability in mass balance and no clear trend for this region so we consider this to be a reasonable approximation (Luthcke et al., 2008). For smaller regional sources we used recent estimates for the magnitudes and temporal trends (Dyurgerov and Meier, 2005; Hock et al., 2009; Kaser et al., 2006; Meier et al., 2007; Chen et al., 2007; Wouters et al., 2008). Table 1 indicates the mass trends assumed for the seven regions considered here. The total mean flux over the nine year period 2000-2008 is $497 \mathrm{Gt} \mathrm{yr}^{-1}$, which is equivalent to $1.4 \mathrm{~mm} \mathrm{yr}^{-1}$ eustatic SLR. The Himalayas were excluded for reasons explained elsewhere (supplementary information). It is important to note, however, that this flux is time-evolving, including during the period of interest in this study (Meier et al., 2007; Rignot et al., 2008a; Velicogna, 2009). As a consequence, both the amplitude and pattern of RSL considered here may change in the future.

\section{Results and discussion}

The distribution of mass loss/gain is not uniform over the three major source areas (Fig. 1) and this has important consequences for the pattern of sea level variations due to these sources (cf. Fig 3). Mass loss in Greenland is dominated by dynamic thinning in the south east and enhanced ablation around the margins (Fig. 1), especially along the southern half of the ice sheet (Ettema et al., 2009; van den Broeke et al., 2009). This pattern of mass loss results in a RSL lowering for the whole of the UK, Scandinavia Iceland, Quebec, the Hudson Bay and Nunavut (Fig. 2a). There is a negligible impact on the rest of northern Europe including 
Table 1. Regional distribution of ice mass losses for 2000-2008 inclusive. Column three refers to the primary source for relative spatial distribution of losses. The uncertainties quoted in column 2 are scaled values obtained from the source text, where available. They are scaled so that the ratio of the error vs. mass trend is the same here as in the original cited reference. They do not indicate our assessment of the uncertainty in mass trends from each source and may be an underestimate of this. For mountain glaciers and ice cap regions the source references were not always explicit about the relative contributions. For NW USA we referred to Dyurgerov and Meier to determine the relative contributions but ensured that the total for non-ice sheet contributions agreed with Meier et al., 2007 and Dyurgerov and Meier, 2005. Our estimates for Greenland and Antarctica include MG\&IC not connected to the ice sheets.

\begin{tabular}{lcll}
\hline Region & $\begin{array}{c}\text { Mean mass loss } \\
\text { 2000-2009 Gt yr }\end{array}$ & Primary source & $\begin{array}{l}\text { Epoch for } \\
\text { primary source }\end{array}$ \\
\hline Greenland & $166 \pm 34^{1}$ & van den Broeke et al. (2009) & $1996-2008^{2}$ \\
Antarctica & $135 \pm 61$ & Rignot et al. (2008) ${ }^{2}$, Veilcogna (2009) & $1996-2006,2003-2008$ \\
Alaska & $61 \pm 5$ & this study & $2003-2008$ \\
Canadian Arctic & $50 \pm 28$ & Hock et al. (2009) & $1961-2004$ \\
Svalbard & $10 \pm 3$ & Wouters et al. (2008) & $2003-2008$ \\
Patagonia & $30 \pm 11$ & Chen et al. (2007) & $2002-2006$ \\
NW USA & $45 \pm 9^{3}$ & Meier et al. (2007); Dyurgerov and Meir (2005) & $1995-2004^{4}$ \\
\hline
\end{tabular}

(1) no uncertainties are given in this paper for the mean trend. Here, we used the errors RMS errors for the SMB (Ettema et al., 2009) and discharge (Rignot et al., 2008b). (2) Two estimates are provided: a net flux and net+. We use the latter, which is scaled to include unsurveyed areas and, therefore, includes a proportion of MG\&IC in Meier et al., 2007. We also reduce losses in sector HH', as explained in the text, to provide greater consistency with GRACE and radar altimetry. The contribution of MG\&IC around the periphery of Greenland is less significant and estimated to be around 25\% of that for Antarctica for the period 1961-2004 (Hock et al., 2009). (3) We used the relative error estimate for 2004 for all MG\&IC combined from Meir et al. (2007). (4) the epoch quoted here is from Meir et al. (2007) which is for all MGIC combined.

the Netherlands, Atlantic coastline of Germany and along the Arctic coastline of Russia (Fig. 2a). The spatial pattern differs significantly from an earlier result that assumed uniform wastage across the ice sheet (cf. Fig. 3), which has the effect of pushing the zero RSL contour further north (Mitrovica et al., 2001). The far-field peak increase is less dependent on the precise pattern of mass loss and occurs in the South Atlantic and around the southern tip of Chile and Argentina, in broad agreement with an earlier study (Mitrovica et al., 2001). Mass loss from Antarctica is concentrated in key sectors of West Antarctica and the Peninsula (Fig. 1). This has a marked effect on the zonal distribution of RSL, resulting in maxima around the coastline of North America and Australasia (Fig. 2b). In this region the increase is about $30 \%$ higher than the eustatic value (Bamber et al., 2009; Mitrovica et al., 2009).

Mass loss from the Gulf of Alaska results in RSL lowering over the northern Pacific Ocean and over most of the northern coastline of Canada (Fig. 2c). Sea level rise in the southern hemisphere is modest from this source $\left(\sim 0.2 \mathrm{~mm} \mathrm{yr}^{-1}\right)$ as the mass loss rate is less than half that of either ice sheet and does not appear to be accelerating (Luthcke et al., 2008). MG\&IC losses are concentrated, primarily, in the high Arctic and Patagonia (Fig. 1) with the largest RSL effects close to these regions (Fig. 2d). Losses from MG\&IC appear to be increasing (Meier et al., 2007) but at a more modest rate compared with the ice sheets, which are now the dominant source of mass to the oceans (van den Broeke et al., 2009; Velicogna, 2009). There is a large relative uncertainty in the individual MG\&IC contributions (Dyurgerov and Meier, 2005 ) but in absolute terms, the errors are small (in the range $10-20 \mathrm{Gt} \mathrm{yr}^{-1}$ ) compared with the contributions from the

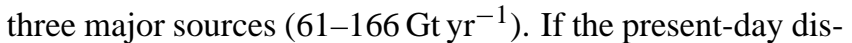
tributions of ice loss are maintained in the future, then the patterns of RSL in Fig. 2 will be the same but the amplitudes will increase linearly with time. We discuss this point in greater detail, later.

The impact of a uniform, nominal mass loss from the continental ice on RSL has been discussed extensively in the literature, (Clark and Lingle, 1977; Farrell and Clark, 1976; Mitrovica et al., 2001). What is unique about our study is that we use observed magnitudes and distributions of mass trends from the larger sources. It is interesting to consider, therefore, the importance of the latter on the RSL fingerprint. This is shown in Fig. 3, for Greenland and the whole of Antarctica. As expected, the largest differences are in the near field and are limited to the North Atlantic in the case of Greenland. In terms of identifying the "fingerprint" of Greenland melt the difference between a uniform mass loss and the observed one is a small. In the case of Antarctica, this is not the case. Significant (in percentage terms) differences extend far into the Pacific and South Atlantic Oceans and have a marked effect on the zonal pattern of RSL changes. The difference between distributing the loss evenly over the WAIS is less marked and mainly impacting RSL around the Antarctic Peninsula (not shown).

It is important to consider the separate fingerprints of RSL from the major sources to investigate their individual gravitationally-consistent "fingerprints", but for present-day and future trends in sea level, it is the combined signal that is important. To first order, this can be approximated as the sum of the individual sources. We show the combined RSL changes, from all land ice sources considered, in Fig. 4. In this case the maxima in RSL $(\sim 1.23$ times eustatic) are 

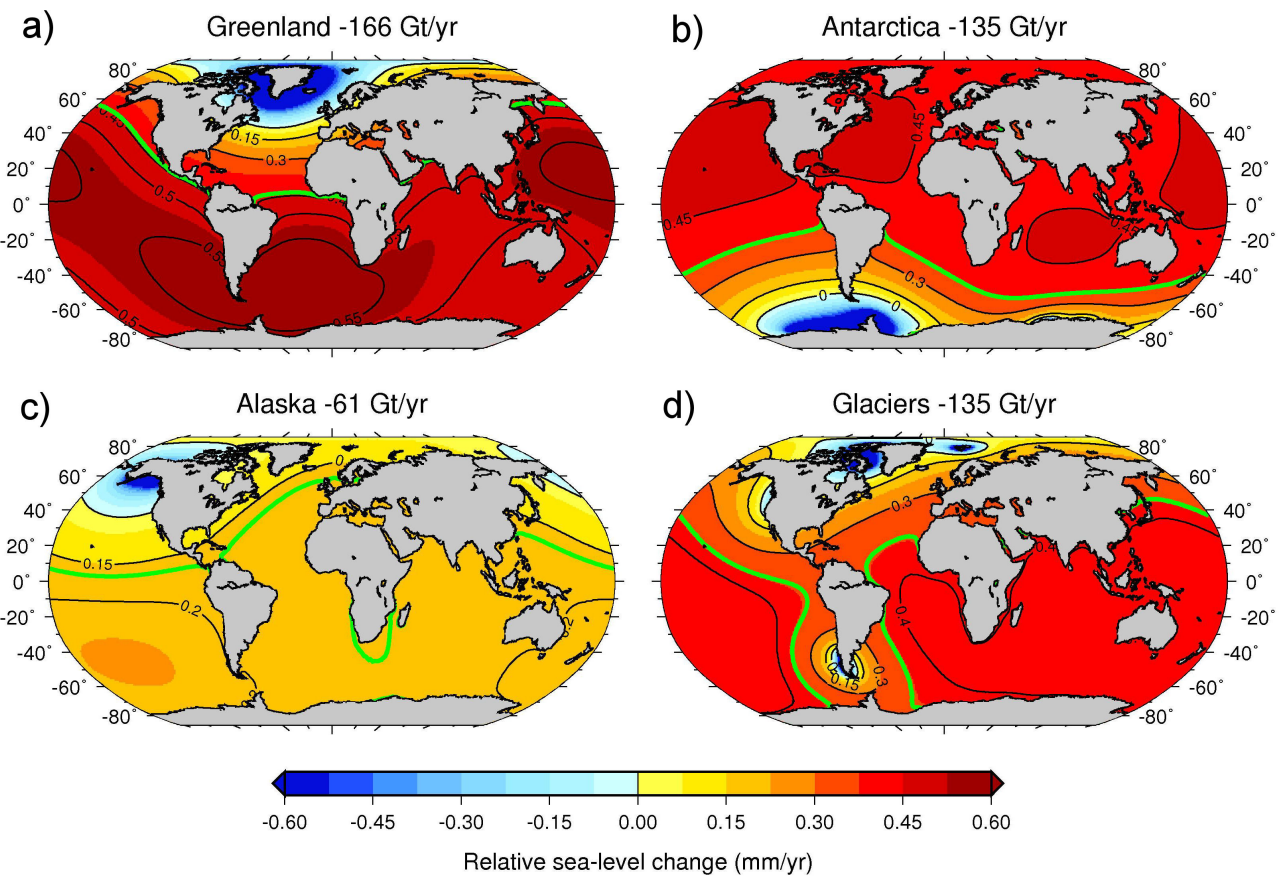

Fig. 2. Relative sea level variations due the gravitational and Earth rotational effects of ice mass losses from different sources for the period 2000-2008 inclusive; (a) Greenland, (b) Antarctica, (c) Alaska, (d) mountain glaciers and ice caps in the Arctic, Patagonia and Rockies. The thick green contour indicates the global average eustatic RSL for each source.

concentrated in a zonal band from about $20^{\circ} \mathrm{N}$ to $40^{\circ} \mathrm{S}$ in the Western Pacific and Indian Oceans, encompassing a number of islands that are particularly vulnerable to sea level rise (Nicholls and Tol, 2006), while Northern Europe experiences a RSL rise that is $\sim 45 \%$ less than eustatic. This is equivalent to rates of 1.6 and $0.8 \mathrm{~mm} \mathrm{yr}^{-1}$, respectively. Thus, the recent, gravitationally consistent, sea level signature due to ice melt is a factor two larger for Australasia and Oceania than it is for Northern Europe.

Figures 2-4 show estimates accounting for ice melt only. Another major long-term, secular trend in RSL is due to glacio-isostatic adjustment (GIA). This has three effects: vertical motion of the Earth's surface, changes to the gravity field, and TPW. GIA is largest for those land masses that have experienced the greatest changes in ice loading and, in particular, for North America and Fennoscandia (Fig. S1). Close to the coast, continental uplift can result in a negative RSL signal, particularly for the Northern Hemisphere (Fig. S1). The low-latitude impact, where the land ice signal peaks in Fig. 4, is, however, negligible. Thus, overall, GIA and uncertainties in estimating it, have little impact on the regions of maximum RSL shown in Fig. 4.

In addition to GIA and surficial mass exchanges, there are two processes within the oceans that affect relative sea level. Steric effects (density changes due to salt and heat content variations) were responsible for about a quarter of the total SLR rise over the last 50 years, increasing to almost a half since 1993 but with large regional variations (Lombard et al.,
2005; Nerem et al., 2006). Steric increases are, thus, both spatially and temporally highly variable. Some of this variability can be explained by major climate oscillations such as the El Nino Southern Oscillation and ocean currents (Nerem et al., 2006; Church et al., 2004). Not surprisingly, over multi-decadal time scales the spatial variations become less pronounced and almost an order of magnitude smaller in rate (Church et al., 2004). A further, transient signal is the effect that freshwater fluxes from ice melt have on ocean circulation (Stammer, 2008) and related dynamic effects due to predicted climate change (Yin et al., 2009). Locally, these can be significant (tens of centimetres deviation from the mean) but a critical difference between these effects and those due to land ice melt is that they are transient and have a mean of zero. In this case, the ocean circulation response is not a rate (i.e. it is not cumulative) but an absolute sea surface height anomaly that is related to the magnitude of the freshwater flux entering the ocean (Stammer, 2008) and the change in the strength, for example, of the Atlantic meridional overturning circulation (Yin et al., 2009). There are other sources of RSL that have a secular-like signature such as water impoundment (Fiedler and Conrad, 2010), which should be included when considering the integrated sea level signal measured by, for example, satellite altimetry.

Considering the land ice contribution to the gravitationally consistent RSL trends over the last $\sim$ decade, we find that for the Western Pacific and Indian Ocean's the increase is about $23 \%$ higher than the eustatic mean of $1.4 \mathrm{~mm} \mathrm{yr}^{-1}$ (Fig. 4). 

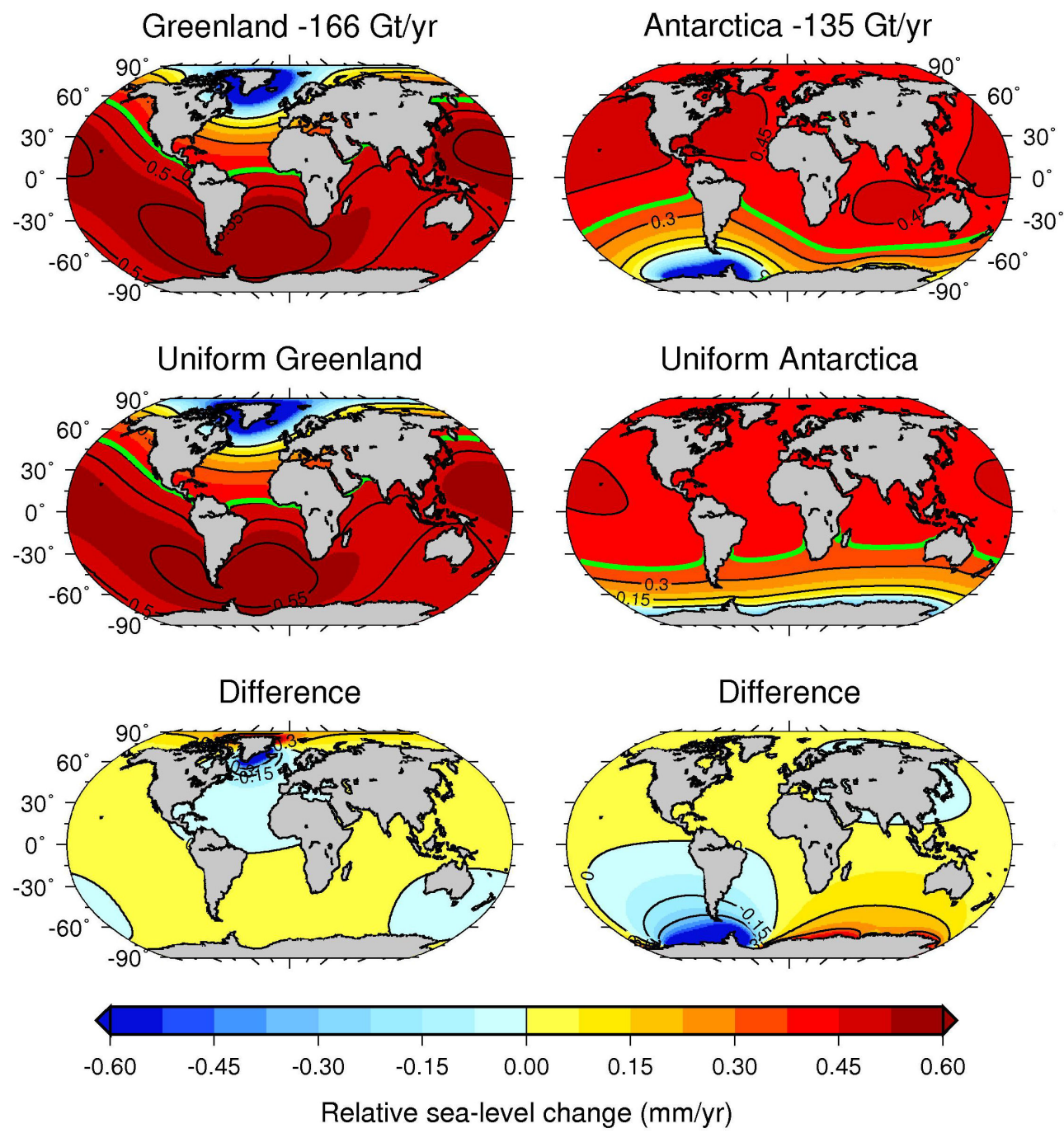

Fig. 3. Impact on relative sea level assuming uniform mass loss over Greenland, and the whole of Antarctica compared with the distribution shown in Fig. 1. The top panel is the same as Fig. 2a and b; the middle panel is for mass loss uniformly distributed across the ice mass and the bottom panel the difference between the two (observed-uniform).

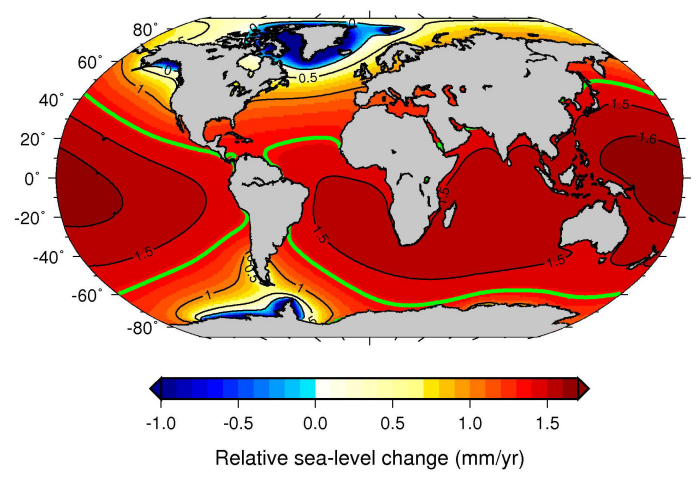

Fig. 4. The combined relative sea level variations for all ice masses. The thick green contour indicates the global average eustatic RSL $\left(1.4 \mathrm{~mm} \mathrm{yr}^{-1}\right)$.
Thus, the current pattern of ice melt, which is dominated by roughly equal losses from Antarctica and Greenland, if continued into the future, will result in a substantially smaller RSL increase for Northern Europe, the Baltic coastline and Arctic North America and, comparatively, about twice the RSL increase for an area that includes Micronesia, the Solomon and Marshal Islands, French Polynesia, the Maldives, South Asia and many small Atolls. This is a region where steric SLR has also been significantly above the global mean value for the last $\sim 15$ years and where the predicted sea surface height anomaly due to ocean dynamics is close to the global mean (Lombard et al., 2005; Nerem et al., 2006; Yin et al., 2009). It is a region that is particularly vulnerable but also particularly ill equipped to adapt to SLR (Nicholls and Tol, 2006). 


\section{Supplementary material related to this article is available online at: http://www.the-cryosphere.net/4/621/2010/ tc-4-621-2010-supplement.pdf.}

Acknowledgements. JLB was funded by UK Natural Environment Research Council grant NE/E004032/1 and a Colorado University Cooperative Institute for Research in Environmental Sciences (CIRES) fellowship. We would like to thank the two referees for their constructive comments.

Edited by: I. M. Howat

\section{References}

Bamber, J. L., Riva, R. E. M., Vermeersen, B. L. A., and LeBrocq, A. M.: Reassessment of the Potential Sea-Level Rise from a Collapse of the West Antarctic Ice Sheet, Science, 324, 901-903, doi:10.1126/science.1169335, 2009.

Berthier, E., Schiefer, E., Clarke, G. K. C., Menounos, B., and Remy, F.: Contribution of Alaskan glaciers to sea-level rise derived from satellite imagery, Nat. Geosci., 3, 92-95, doi:10.1038/ngeo737, 2010.

Bevis, M., Kendrick, E., Smalley Jr, R., Dalziel, I., Caccamise, D., Sasgen, I., Helsen, M., Taylor, F. W., Zhou, H., Brown, A., Raleigh, D., Willis, M., Wilson, T., and Konfal, S.: Geodetic measurements of vertical crustal velocity in West Antarctica and the implications for ice mass balance, Geochem. Geophys. Geosyst., 10, doi:10.1029/2009gc002642, 2009.

Chen, J. L., Wilson, C. R., Tapley, B. D., Blankenship, D. D., and Ivins, E. R.: Patagonia icefield melting observed by gravity recovery and climate experiment (GRACE), Geophys. Res. Lett., 34, L22501, doi:10.1029/2007g1031871, 2007.

Chen, J. L., Wilson, C. R., Blankenship, D., and Tapley, B. D.: Accelerated Antarctic ice loss from satellite gravity measurements, Nature Geoscience, 2, 859-862, doi:10.1038/ngeo694, 2009.

Church, J. A., White, N. J., Coleman, R., Lambeck, K., and Mitrovica, J. X.: Estimates of the regional distribution of sea level rise over the 1950-2000 period, J. Climate, 17, 2609-2625, 2004.

Clark, J. A. and Lingle, C. S.: Future Sea-Level Changes Due to West Antarctic Ice Sheet Fluctuations, Nature, 269, 206-209, 1977.

Dyurgerov, M. and Meier, M. F.: Glaciers and the changing Earth System: A 2004 snapshot, INSTAAR, University of Colorado at Boulder, Boulder, 118, 2005.

Ettema, J., van den Broeke, M., van Meijgaard, E., van de Berg, W., Bamber, J. L., Box, J. E., and Bales, R. C.: Higher surface mass balance of the Greenland ice sheet revealed by highresolution climate modeling, Geophys. Res. Lett., 36, L12501, doi:10.1029/2009GL038110, 2009.

Farrell, W. E. and Clark, J. A.: Postglacial sea-level, Geophys. J. R. astr. Soc., 46, 647-667, 1976.

Fiedler, J. W. and Conrad, C. P.: Spatial variability of sea level rise due to water impoundment behind dams, Geophys. Res. Lett., 37, L12603, doi:10.1029/2010g1043462, 2010.
Hock, R., de Woul, M., Radic, V., and Dyurgerov, M.: Mountain glaciers and ice caps around Antarctica make a large sea-level rise contribution, Geophys. Res. Lett., 36, L07501, doi:10.1029/2008g1037020, 2009.

Horwath, M. and Dietrich, R.: Signal and error in mass change inferences from GRACE: the case of Antarctica, Geophys. J. Int., 177, 849-864, doi:10.1111/j.1365-246X.2009.04139.x, 2009.

Kaser, G., Cogley, J. G., Dyurgerov, M. B., Meier, M. F., and Ohmura, A.: Mass balance of glaciers and ice caps: Consensus estimates for 1961-2004, Geophys. Res. Lett., 33, L19501, doi:10.1029/2006GL027511, 2006.

Lombard, A., Cazenave, A., Le Traon, P. Y., and Ishii, M.: Contribution of thermal expansion to present-day sealevel change revisited, Glob. Planet. Change, 47, 1-16, doi:10.1016/j.gloplacha.2004.11.016, 2005.

Luthcke, S. B., Arendt, A. A., Rowlands, D. D., McCarthy, J. J., and Larsen, C. F.: Recent glacier mass changes in the Gulf of Alaska region from GRACE mascon solutions, J. Glaciol., 54, 767-777, 2008.

Meier, M. F., Dyurgerov, M. B., Rick, U. K., O’Neel, S., Pfeffer, W. T., Anderson, R. S., Anderson, S. P., and Glazovsky, A. F.: Glaciers dominate Eustatic sea-level rise in the 21st century, Science, 317, 1064-1067, doi:10.1126/science.1143906, 2007.

Milne, G. A. and Mitrovica, J. X.: Postglacial sea-level change on a rotating Earth, Geophys. J. Int., 133, 1-19, 1998.

Mitrovica, J. X., Tamisiea, M. E., Davis, J. L., and Milne, G. A.: Recent mass balance of polar ice sheets inferred from patterns of global sea-level change, Nature, 409, 1026-1029, 2001.

Mitrovica, J. X., Gomez, N., and Clark, P. U.: The Sea-Level Fingerprint of West Antarctic Collapse, Science, 323, 753-753, doi:10.1126/science.1166510, 2009.

Nerem, R. S., Leuliette, E., and Cazenave, A.: Present-day sea-level change: A review, C. R. Geosci., 338, 1077-1083, doi:10.1016/j.crte.2006.09.001, 2006.

Nicholls, R. J. and Tol, R. S. J.: Impacts and responses to sea-level rise: a global analysis of the SRES scenarios over the twenty-first century, Philos. T. R. Soc. A., 364, 1073-1095, 2006.

Rignot, E., Bamber, J. L., van den Broeke, M. R., Davis, C., Li, Y., van de Berg, W. J., and van Meijgaard, E.: Recent Antarctic ice mass loss from radar interferometry and regional climate modelling, Nat. Geosci., 1, 106-110, doi:10.1038/ngeo102, 2008a.

Rignot, E., Box, J. E., Burgess, E., and Hanna, E.: Mass balance of the Greenland ice sheet from 1958 to 2007, Geophys. Res. Lett., 35, L20502, doi:10.1029/2008g1035417, 2008b.

Rowlands, D. D., Luthcke, S. B., McCarthy, J. J., Klosko, S. M., Chinn, D. S., Lemoine, F. G., Boy, J. P., and Sabaka, T. J.: Global mass flux solutions from GRACE: A comparison of parameter estimation strategies-Mass concentrations versus Stokes coefficients, J. Geophys. Res.-Earth, 115, B01403, doi:10.1029/2009jb006546, 2010.

Slobbe, D. C., Ditmar, P., and Lindenbergh, R. C.: Estimating the rates of mass change, ice volume change and snow volume change in Greenland from ICESat and GRACE data, Geophys. J. Int., 176, 95-106, doi:10.1111/j.1365-246X.2008.03978.x, 2009.

Stammer, D.: Response of the global ocean to Greenland and Antarctic ice melting, J. Geophys. Res.-Oceans, 113, 16, C06022, doi:10.1029/2006jc004079, 2008. 
van den Broeke, M., Bamber, J., Ettema, J., Rignot, E., Schrama, E., van de Berg, W. J., van Meijgaard, E., Velicogna, I., and Wouters, B.: Partitioning Recent Greenland Mass Loss, Science, 326, 984-986, doi:10.1126/science.1178176, 2009.

Velicogna, I.: Increasing rates of ice mass loss from the Greenland and Antarctic ice sheets revealed by GRACE, Geophys. Res. Lett., 36, L19503, doi:10.1029/2009g1040222, 2009.

Woodward, R. S.: On the form and position of mean sea level, US Geol. Surv. Bull., 87-170, 1888.

Wouters, B., Chambers, D., and Schrama, E. J. O.: GRACE observes small-scale mass loss in Greenland, Geophys. Res. Lett., 35, L20501, doi:10.1029/2008g1034816, 2008.
Wu, X. P., Heflin, M. B., Schotman, H., Vermeersen, B. L. A., Dong, D. A., Gross, R. S., Ivins, E. R., Moore, A., and Owen, S. E.: Simultaneous estimation of global present-day water transport and glacial isostatic adjustment, Nat. Geosci., 3, 642-646, doi:10.1038/ngeo938, 2010.

Yin, J. J., Schlesinger, M. E., and Stouffer, R. J.: Model projections of rapid sea-level rise on the northeast coast of the United States, Nat. Geosci., 2, 262-266, doi:10.1038/ngeo462, 2009.

Zwally, H. J., Giovinetto, M. B., Li, J., Cornejo, H. G., Beckley, M. A., Brenner, A. C., Saba, J. L., and Donghui, Y.: Mass changes of the Greenland and Antarctic ice sheets and shelves and contributions to sea-level rise: 1992-2002, J. Glaciol., 51, 509-527, 2005. 